\title{
Application of Chitin and Zeolite adsorbents for treatment of low level radioactive liquid wastes
}

\author{
${ }^{1}$ F. Moattar and ${ }^{2 *}$ S. Hayeripour \\ ${ }^{I}$ Atomic Energy Organization of Iran, Nuclear Research Center, P.O.B.11365-3486, Tehran, Iran \\ ${ }^{2}$ Department of Environmental Science, Graduate School of the Environment and Energy, Islamic Azad University,
}

Science and Research Campus, Tehran, Iran

\begin{abstract}
Two types of Shrimp Chitin derivatives and two types of Iranian natural Zeolite derivatives (Firuzkooh Clinoptiliolite) were studied for adsorption and treatment of low-level radioactive liquid waste (LLW). Chitin with lowers than $10 \%$ and Chtiosan with higher than $90 \%$ deacetylation factor were selected as natural organic adsorbents. Natural Cliniptilolite of Firuzkooh area and $\mathrm{Na}$ form derivatives of it were selected as natural inorganic adsorbents. The static and dynamic ion exchange experimental results show that the adadsorption efficiency depend on particle size, PH, adsorbent type, deacetylation factor (in Chitin adsorbents) and cation type. The best Cs adsorption occurred in Na form Clinoptilolite. Nevertheless Chitin derivatives, particularly Chitosan, are more efficient than Zeolite adsorbents for removing of radionuclides such as ${ }^{137} \mathrm{Cs},{ }^{54} \mathrm{Mn},{ }^{90} \mathrm{Sr}$ and ${ }^{60} \mathrm{Co}$. Adsorption performance was discussed and compared with each other.
\end{abstract}

Key words: Chitin, Chitosan, Clinoptilolite, adsorption, radionuclides

*Corresponding Author, E-mail:samhaeri@yahoo.com,

\section{Introduction}

Various kinds of adsorbents have been widely produced and applied for the removal of radionuclides and heavy metals (Kuribayashi et al., 1987). Among these, synthetic resins show high selectivity for the removal of metallic ions in liquid waste with high electric conductivity. Although this group of resins has excellent performance, the cost is relatively high in comparison with the ordinary type of ion exchange resins. This is due to the complexity of the synthetic producing process (Kuribayashi et al., 1988). Chitin has been widely used for cosmetics, fed additives and so on due to it being a harmless and inexpensive material. Muzzarerlli et al. showed the adsorption performance of Chitin. It has been shown that some kinds of Chitosan derivatives remove heavymetals from solutions (Muzzarelli, 1973, 1985, Muzzarelli et al., 1986). Zeolite is a naturally occurring mineral group consisting of over 50 different minerals (Zamzow et al., 1987). Made of a special crystalline structure that is porous but remains rigid in the presence of water, Zeolite can be adapted for a variety of use such as household odor control products, water and waste water treatment and so on (Kesraoul-Ouki, et al., 1990 and Cheeseman, et al., 1993 and leppertid, 1990).
It could be possible for the chitin and Zeolite derivatives to be applied to radioactive waste management if they show good performance for radionuclides removal in radioactive liquid waste (Cheeseman, et al., 1993 and Bailey, et al., 1999). Our objective is to evaluate the applicability of shrimp Chitin adsorbents compared to Iranian natural Clinoptilolite (from Firuzkooh area) to lowlevel radioactive liquid waste treatment.

\section{Materials and Methods}

Two types of Chitin and two types of Zeolite adsorbents were prepared for the static and dynamic experiments. Glass tube of inner diameter $2.5 \mathrm{~cm}$ filled with chitin adsorbents and $2 \mathrm{~cm}$ filled with Zeolite adsorbents were used as columns for dynamics experiments. Chitin and Chitiosan were extracted from Shrimp shell waste with $<10 \%$ and $>90 \%$ deacetilation factor respectively (Ravi Kumar, 1999). Zeolite mines of Firuzkooh area prepared Iranian natural Clinoptiliolite (Zeo1) and sodium form Clinoptilolite (ZeoNa). General characteristics of adsorbent are shown in Table1. Three types of simulation solution were prepared to study and compare the adsorption performance. The chemical 
composition is shown in Table2. Solution group one is mono cationic and consists of stable isotopes Solution group two is consist of 3 stable cations of $\mathrm{Cs}, \mathrm{Sr}$ and $\mathrm{Co}$ and solution group 3 is a simulated radioactive waste consists Cs-137, Co-60 and Mn-54. This solution prepared by adding of Cs-137, Co- 60 and Mn-54 to de-ionized water.

Gamma spectrometry was applied for a quantitative analysis of these radionuclide and ICP_AA used for measuring of stable radioisotopes.

In static experiments the solution volume was $25 \mathrm{ml}$. Weight of added adsorbent was $500 \mathrm{mg}$. The solution was put into glass beaker and mixed with the weighed adsorbent by magnetic stirrer. After definite period of time (Table 2) the samples were taken $(2 \mathrm{ml})$, it was centrifuged to be separated from the adsorbent and then $1 \mathrm{ml}$ of it was placed in tubes

for

ICP-AA spectrophotometer. Distribution coefficient $\left(\mathrm{K}_{\mathrm{d}}\right)$ was measured for each stable isotope. The $K_{d}$ was calculated by equation (1):

$\mathrm{K}_{\mathrm{d}(\mathrm{m} / \mathrm{g})}=\left[\left(\mathrm{A}_{\mathrm{o}}-\mathrm{A}_{\mathrm{eq}}\right) / \mathrm{A}_{\mathrm{eq}}\right] \times \mathrm{V} / \mathrm{M}$

Ao: initial concentration of cation in solution

Aeq: concentration of cation after adsorption

$\mathrm{V}$ : solution volume $(\mathrm{ml})$

$\mathrm{M}$ : Weight of the adsorbent ( $\mathrm{g}$ )

For obtaining the breakthrough curve the volume of the adsorbent bed was about $6 \mathrm{~cm}^{3}$. The volume of simulated radioactive waste was about $600 \mathrm{~cm}^{3}$. The input flow rate was about $1 \mathrm{ml} / \mathrm{min}$.

\section{Results}

\section{Static methods}

Figure 1 has shown maximum Distribution coefficient $\left(\mathrm{K}_{\mathrm{d}}\right)$ of Chitin, Chitosan, Zeo1 and $\mathrm{ZeoNa}$ is treated by solution 1. Maximum adsorption of chitin adsorbents occurred with in 45 minutes. Nevertheless major portion of these values belongs to the first 20 minutes and by increasing of treatment time over 45 minutes no effect on $K_{d}$ was observed.

Chitin and Chitosan have shown max adsorption in Co solution and $\mathrm{min}$ in $\mathrm{Sr}$ solution. Increase in solution concentration, shift this manner to $\mathrm{Co}>\mathrm{Sr}>\mathrm{Cs}$. Optimum $\mathrm{pH}$ for Chitin adsorbent was 5 and lower or higher
$\mathrm{pH}$ has shown sensible decrease in $\mathrm{K}_{\mathrm{d}}$. The best adsorb ion performance in Chitosan was seen in $\mathrm{pH}=6.5$. However the best adsorption was seen at lower $\mathrm{pH}$ but some practical problems occurred due to solubility of Chitosan at $\mathrm{pH}$ lower than 6.5.

Zeolite adsorbents reached maximum adsorption in the longer treating time about 12-15 hours, with the major portion of adsorption occurred in 6 hours. Zeolite adsorption depended on $\mathrm{pH}$ solution and the optimum $\mathrm{pH}$ was 8.7. As shown in Figure1 and 2, maximum adsorption belongs to $\mathrm{Cs}$ on $\mathrm{Na}$ form Clinoptilolite and minimum to $\mathrm{Sr}$ on natural Clinoptilolite. Clinoptilolite adsorption follows $\mathrm{Cs}>\mathrm{Co}>\mathrm{Sr}$ manner in both cases. By increasing concentration, $\mathrm{K}_{\mathrm{d}}$ has been decreased but there was no observed effect on the adsorption manner. Figure 2 shows max adsorbent $K_{d}$ with the treatment of solution2. The treating time and optimal $\mathrm{PH}$ were similar to solution 1 cases. In this case, maximum $\mathrm{K}_{\mathrm{d}}$ occurred nearly the same time as solution 1 and similarly decreasing of $\mathrm{Kd}$ occurred by the increasing of cation concentration. In Chitin adsorbents, cation adsorption by solution 2 followed the $\mathrm{Co}>\mathrm{Sr}>\mathrm{Cs}$ mode and in Clinoptilolite case, follow the same mode as solution 1 .

\section{Dynamic method}

Figure3 show the breakthrough curve by chitin. ${ }^{60} \mathrm{Co}$ eluted first in about 10 bed volumes. In about 60 bed volumes it reaches to the breakthrough. ${ }^{54} \mathrm{Mn}$ starts to appear in 5 bed volumes, and by 70 bed volumes it reaches the breakthrough. In about 10 bed volumes ${ }^{137} \mathrm{Cs}$ starts to appear and by about 60 bed volumes it reaches to breakthrough points. The breakthrough curve for Chitosan is shown in Figure 4. As it could be expected from the $\mathrm{K}_{\mathrm{d}}$ Co was the best adsorbate and Cs, Mn as follows. Cs elution starts in 20 bed volumes by the column and at 100 bed volumes reached to $95 \%$ of breakthrough. The ${ }^{60} \mathrm{Co}$ started to appear in 40 bed volumes and $82 \%$ of breakthrough was completed with the 100 bed volumes. The Mn-54 started to appear in effluent at 30 bed volumes and reached to $94 \%$ at 100 bed volumes. The breakthrough curve for ZeoNa is shown in Figure 5. Cs was the best adsorbate in comparison with $\mathrm{Co}$ and $\mathrm{Mn}$. Cs elution started in 20 bed volumes and at 100 bed volumes reached to $87 \%$ of breakthrough. The ${ }^{60} \mathrm{Co}$ and ${ }^{54} \mathrm{Mn}$ started to appear at 5 bed volumes. Both $\mathrm{Mn}$, Co reach to full breakthrough about 40 
Table 1: Characteristics of adsorbents

\begin{tabular}{|c|c|}
\hline Chitin adsorbents characteristics & Zeolite adsorbents characteristics \\
\hline - Fine fiber structure $(20-50$ mesh or $297-840$ & - Fine particle with 50-100mesh (149-297 microns) \\
\hline microns) & - 3-dimensional rigid crystalline structure \\
\hline - Large specific surface & - Molecular sieve \\
\hline - Ability to exchange cations & - Large specific surface \\
\hline - Low production cost & - Ability to exchange cations \\
\hline - High resistively to chemical and radiation effects & - Low production cost \\
\hline - Burnable without producing toxic substances & $\begin{array}{l}\text { - High resistively to radiation effects and low resistively to } \\
\text { acidy condition }\end{array}$ \\
\hline
\end{tabular}

Table 2 : Treatment condition based on solution type

\begin{tabular}{|c|c|c|c|c|c|c|c|c|}
\hline \multirow[b]{2}{*}{$\begin{array}{l}\text { Properties } \\
\text { Type of } \\
\text { solution }\end{array}$} & \multirow[b]{2}{*}{$\begin{array}{l}\text { Isotope } \\
\text { type }\end{array}$} & \multicolumn{4}{|c|}{$\mathrm{pH}$ range } & \multicolumn{2}{|c|}{ Treatment Time } & \multirow[b]{2}{*}{$\begin{array}{l}\text { Experiment } \\
\text { type }\end{array}$} \\
\hline & & Chitin & Chitosan & Zeo1 & ZeoNa & $\begin{array}{c}\text { Chitin } \\
\text { Adsorbents } \\
\text { (Min) }\end{array}$ & $\begin{array}{c}\text { Zeo } \\
\text { Adsorbents } \\
(\mathrm{Hr})\end{array}$ & \\
\hline \multirow{3}{*}{ Solution 1} & $\begin{array}{c}\text { Cs } \\
\text { absolute } \\
\text { solution }\end{array}$ & $3-10$ & $3-10$ & $\begin{array}{l}4.5- \\
10.5\end{array}$ & $\begin{array}{l}4.5- \\
10.5\end{array}$ & $5,15,45$ & $2,6,15$ & Batch \\
\hline & $\begin{array}{l}\text { Co } \\
\text { absolute } \\
\text { solution }\end{array}$ & $3-10$ & $3-10$ & $\begin{array}{l}4.5- \\
10.5\end{array}$ & $\begin{array}{l}4.5- \\
10.5\end{array}$ & $5,15,45$ & $2,6,15$ & Batch \\
\hline & $\begin{array}{c}\text { Sr absolute } \\
\text { solution }\end{array}$ & $3-10$ & $3-10$ & $\begin{array}{l}4.5- \\
10.5 \\
\end{array}$ & $\begin{array}{l}4.5- \\
10.5 \\
\end{array}$ & $5,15,45$ & $2,6,15$ & Batch \\
\hline Solution 2 & $\begin{array}{l}\mathrm{Cs}, \mathrm{Co}, \mathrm{Sr} \\
\text { mixture } \\
\text { solution }\end{array}$ & 5.5 & 6.7 & 8.7 & 8.7 & $5,15,30,60,120$ & $2,6,12,24,36$ & Batch \\
\hline Solution 3 & $\begin{array}{l}{ }^{137} \mathrm{Cs},{ }^{60} \mathrm{Co} \\
\text { and }{ }^{54} \mathrm{Mn} \\
\text { mixture } \\
\text { solution }\end{array}$ & 5.5 & 6.7 & 8.7 & 8.7 & Each 60 min & Each one $\mathrm{Hr}$ & Column \\
\hline
\end{tabular}

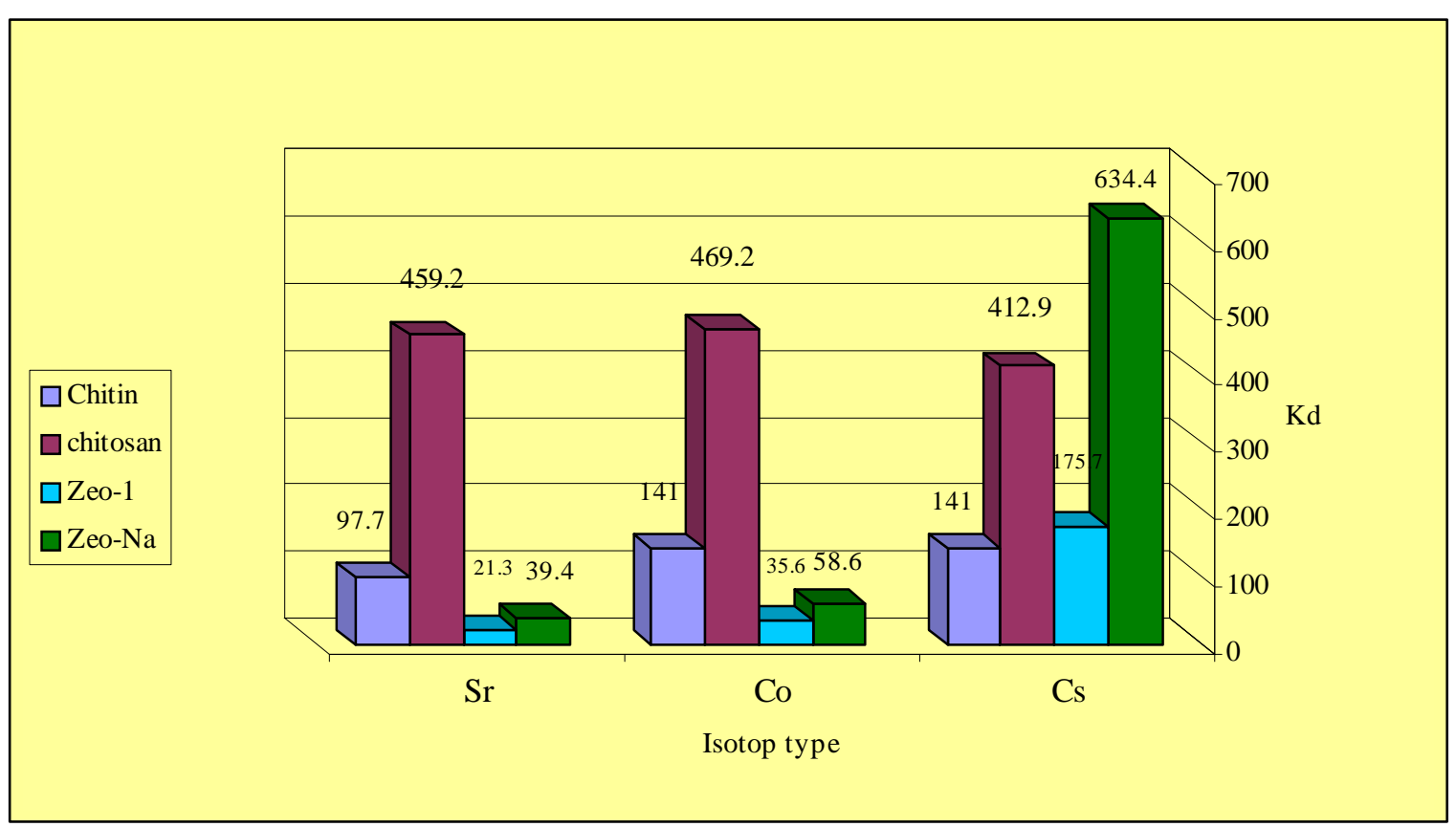

Figure 1: - Kd comparison chart based on adsorbent types and isotopes in solution 1 


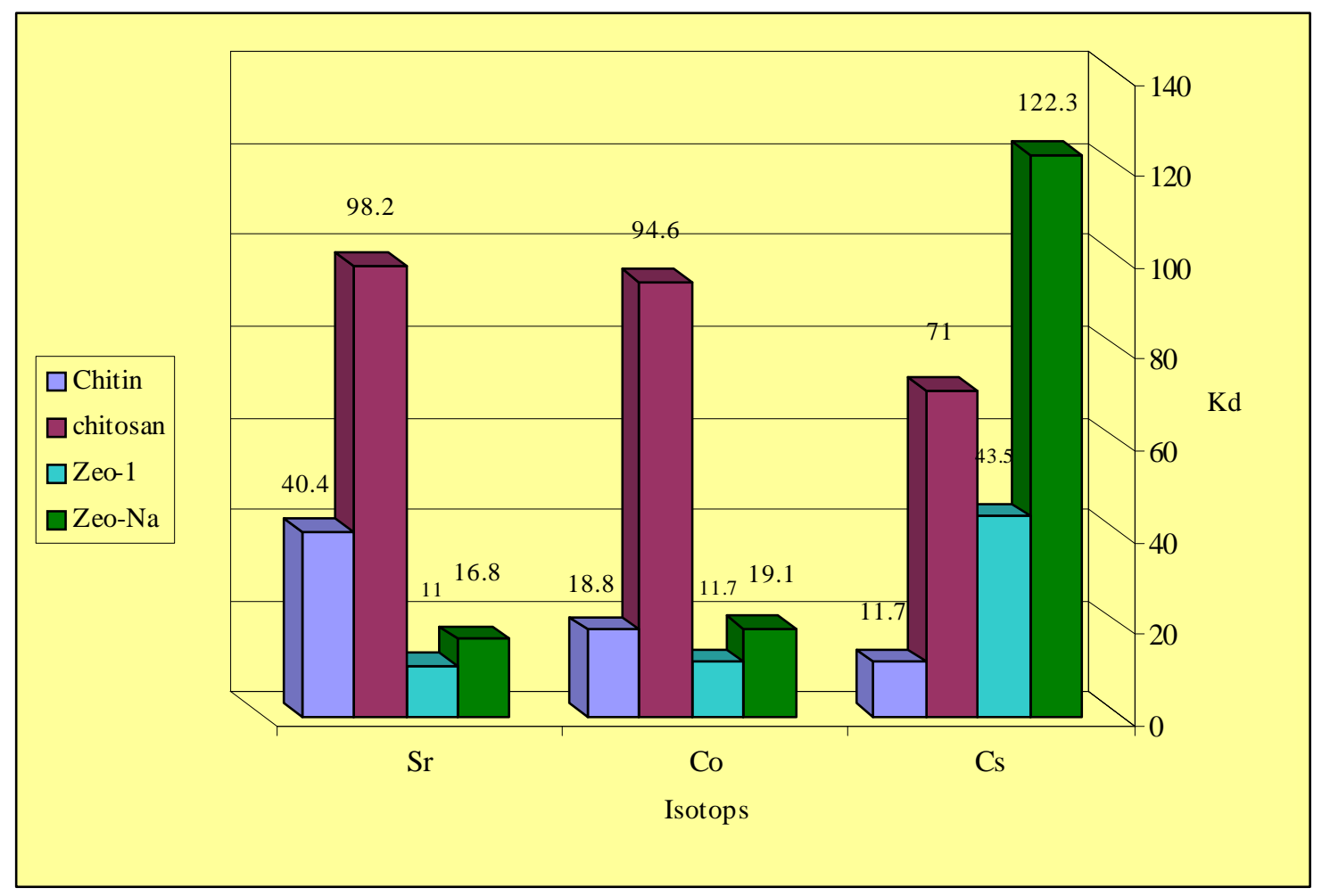

Figure 2: - Kd comparison chart based on adsorbent type and isotopes in solution 2

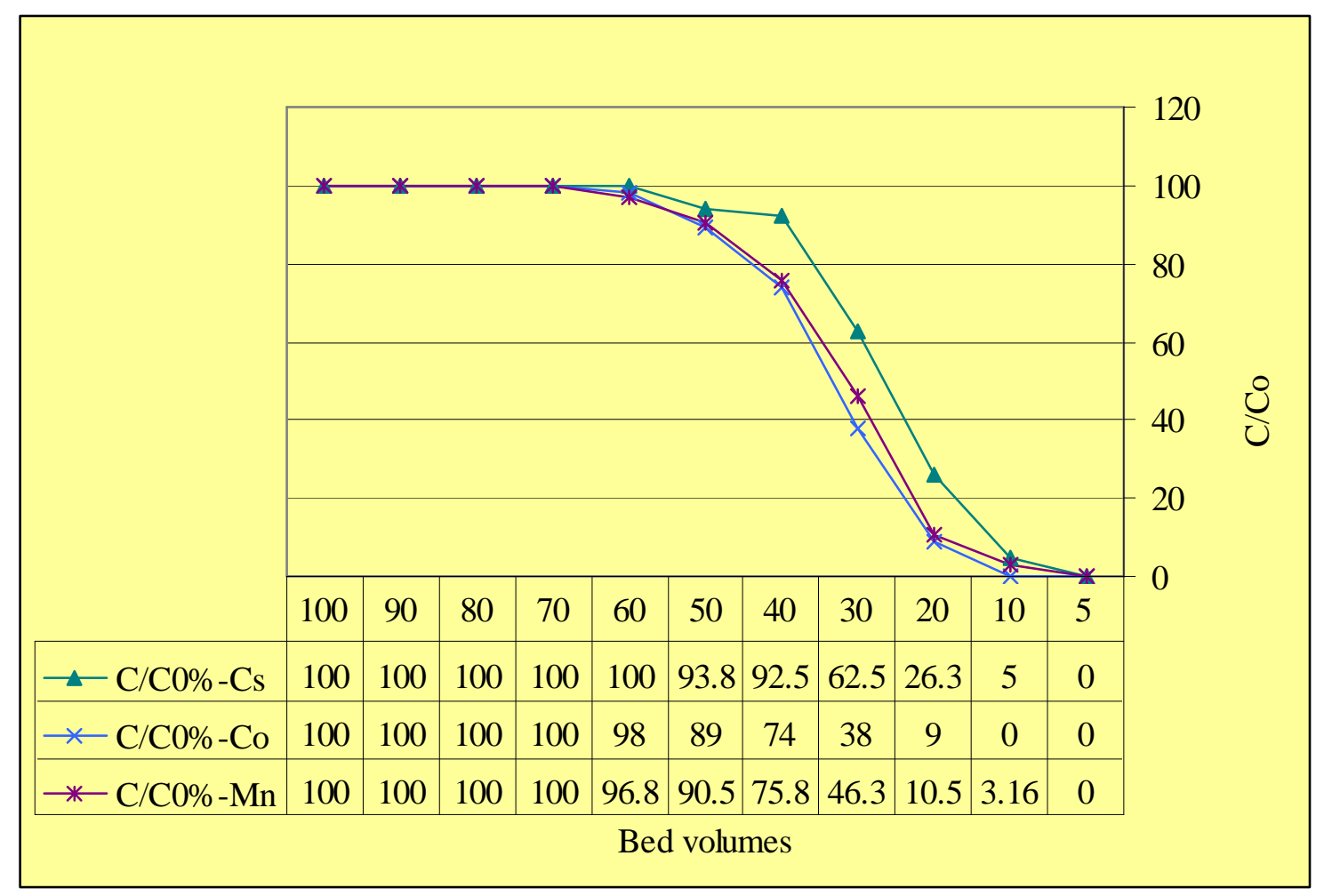

Figure 3: Break-through curve of Chitin 




Bed volumes

Figure 4: Break-through curve of Chitosan



Figure 5: Break-through curve of ZeoNa 
bed volumes. More or less natural Clinoptilolite showed no good effect on solutions and the experiments showed inconsistent results.

\section{Discussion and Conclusion}

Chitin and Chitosan adsorbents are effective for the removal of radionuclide. They can be used as suitable adsorbents for removing of radionuclide and heavy metals. Chitosan adsorbent had the best performance between four examined adsorbents. In this study natural Iranian Clinoptilolite (Firuzkooh area) showed the weakest performance among the adsorbents. $\mathrm{Na}$ form Clinoptilolite showed the best adsorption for $\mathrm{Cs}$, and the less on $\mathrm{Sr}, \mathrm{Co}, \mathrm{Mn}$ ions.

In conclusion, Chitosan adsorbent can be applied for the treatment of radioactive liquid waste and water if suitable adsorbents were selected based on the solubility and deacetilation factor. Na form Clinoptilolite is suitable for removal of Cs from the solution, which solely contains it. Natural Clinoptilolite was not suitable for radionuclides removal..

\section{Acknowledgement}

The authors would like to express this sincere thanks and appreciations to Dr. J. Nouri Editor-inChief of IJEST for his precious comments and suggestions during the print out of this article.

\section{References}

Bailey S.E., Olin T.J. R.M. Bricka and D. D. A. Adrian Review of Potentially Low-Cost Sorbents for Heavy Metals Water Resources, 33 (11): 2469-2479, 1999

Cheeseman, S., and R. Perry,. "Effects of conditioning and treatment of Chabazite and clinoptilolite prior to lead and cadmium removal Environ. Sci. Technol., 27 (6): 1108-1116, 1993

Kesraoul-Ouki, S., M.J.Zamzow, B.R. Eichbaum, K.R. Sandgren, and D.E. Shanks, Removal of heavy metals and other cations from waste water using Zeolites Sep. Sci. and Technol., 25(13-15): 15551569, 1990

Kuribayashi, H., Y. Kosbiba, K. Suzuki, and M. Shibuya, , Radionuclide Separation process (RASEP) Proc. Waste Management, 3: 89-96, 1987

Kuribayashi, H., M. Watanabe, M. Sbibuya, and K. Suzuki, Selective Separation Process of Radionuclidea in Liquid Waste, Pmt. DOE Model Oak Ridge, USA, 1: 169-174, 1988

Leppert, D., Heavy metal adsorption with clinoptilolite zeolite: alternatives for treating contaminated soil and water., Mining Engineering, 604-608, 1990

Muzzarelli, R. A. A., Natural Chelating Polymers, Pergamon Press, New York, 83-227, 1973

Muzzarelli, R. A. A., Adsorption performance of Chitin carbohydr. Polymers, 5: 85-93, 1985

Muzzarelli R. A. A., C. Jeuniaux and G. W. GoodayEds, Chitin in Nature and Technology, Plenum Press, New York, 337-351 1986

Ravi Kumar, M. N. V. Chitin and Chitosan fibers: An overview on chitin and Chitosan applications Bull. Mater. Sci., 22: 905-9011, 1999

Zamzow, M.J., B.R Eichbaum, K.R. Sandgren, and D.E. Shanks, Removal of heavy metals and other cations from waste water using Zeolites Sep. Sci. and Technol., 25 (13-15): 1555-1569, 1990 